\title{
High prevalence of iodine deficiency in pregnant women living in adequate iodine area
}

\author{
Verônica Carneiro Borges Mioto', Ana Carolina de Castro Nassif Gomes Monteiro², \\ Rosalinda Yossie Asato de Camargo', Andréia Rodrigues Borel ${ }^{3}$, Regina Maria Catarino ${ }^{4}$, Sergio Kobayashi², \\ Maria Cristina Chammas ${ }^{2}$ and Suemi Marui ${ }^{1}$
}

${ }^{1}$ Thyroid Unit, Division of Endocrinology and Metabolism, Hospital das Clinicas HCFMUSP-Faculdade de Medicina, Universidade de Sao Paulo, Sao Paulo, Sao Paulo, Brazil

2Ultrasound Unit, Department of Radiology, Hospital das Clinicas HCFMUSP-Faculdade de Medicina, Universidade de Sao Paulo, Sao Paulo, Sao Paulo, Brazil

${ }^{3}$ Clinic of the Paraisópolis Community Einstein Project, Jewish School of Health Sciences Albert Einstein, Sao Paulo, Sao Paulo, Brazil

${ }^{4}$ Hematology and Biochemistry, Center of Pathology, Adolfo Lutz Institute, Sao Paulo, Sao Paulo, Brazil

Correspondence should be addressed to S Marui: suemimar@usp.br

\begin{abstract}
Objectives: lodine deficiency during pregnancy is associated with obstetric and neonatal adverse outcomes. Serum thyroglobulin (sTg) and thyroid volume (TV) are optional tools to urinary iodine concentration (UIC) for defining iodine status. This cross-sectional study aims to evaluate the iodine status of pregnant women living in iodine-adequate area by spot UIC and correlation with STg, TV and thyroid function.

Methods: Two hundred and seventy-three pregnant women were evaluated at three trimesters. All had no previous thyroid disease, no iodine supplementation and negative thyroperoxidase and thyroglobulin antibodies. Thyroid function and sTg were measured using electrochemiluminescence immunoassays. TV was determined by ultrasonography; UIC was determined using a modified Sandell-Kolthoff method.

Results: Median UIC was $146 \mu \mathrm{g} / \mathrm{L}$, being $52 \%$ iodine deficient and only $4 \%$ excessive. TSH values were $1.50 \pm 0.92,1.50 \pm 0.92$ and $1.91 \pm 0.96 \mathrm{mIU} / \mathrm{L}$, respectively, in each trimester $(P=0.001)$. sTg did not change significantly during trimesters with median $11.2 \mathrm{ng} / \mathrm{mL}$ and only $3.3 \%$ had above $40 \mathrm{ng} / \mathrm{mL}$. Mean TV was $9.3 \pm 3.4 \mathrm{~mL}$, which positively correlated with body mass index, but not with sTg. Only $4.5 \%$ presented with goitre.

When pregnant women were categorized as iodine deficient (UIC $<150 \mu \mathrm{g} / \mathrm{L}$ ), adequate ( $\geq 150$ and $<250 \mu \mathrm{g} / \mathrm{L}$ ) and excessive $(\geq 250 \mu \mathrm{g} / \mathrm{L}$ ), sTg, thyroid hormones and TV at each trimester showed no statistical differences.

Conclusions: lodine deficiency was detected frequently in pregnant women living in iodine-adequate area. STg concentration and TV did not correlate to UIC. Our observation also demonstrated that the Brazilian salt-iodization programme prevents deficiency, but does not maintain iodine status within adequate and recommended ranges for pregnant women.
\end{abstract}

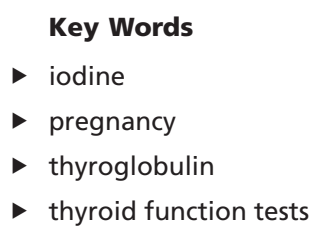

Endocrine Connections (2018) 7, 762-767

\section{Introduction}

Iodine status is a global health concern, particularly in developing countries, and emphasis should be placed on diagnosis and correction at the community level

$\begin{array}{lr}\text { http://www.endocrineconnections.org } & \text { ○ } 2018 \text { The authors } \\ \text { https://doi.org/10.1530/EC-18-0131 } & \text { Published by Bioscientifica Ltd }\end{array}$

rather than the individual due to the high impact in child neurological development and pregnancy outcomes $(1,2)$. 
During pregnancy, daily iodine requirement increases by nearly $50 \%$ because of an increase in renal iodine excretion, increased thyroid hormone production and foetal iodine requirements (3). In iodine-sufficient areas, pregnant women maintain stable total body iodine levels throughout pregnancy. However, in mild-tomoderate iodine-deficient areas, total body iodine stores decline gradually from the first to the third trimester of pregnancy, and the potential changes in the mother's thyroid function during pregnancy are uncertain (4).

The recommended method to evaluate iodine nutrition status in a community of pregnant women is by measuring the urinary iodine concentration (UIC), thyroid size and serum thyroglobulin (sTg) (5). The UIC is most often used, but it indicates current iodine nutrition while thyroid size and sTg concentrations reflect iodine nutrition over a period of months or years. Measurements of UIC in randomly collected urine samples have proven to be useful, and consequently, iodine nutrition is defined as mildly-to-moderately iodine-deficient groups of pregnant women whose median UICs are between 50 and $150 \mu \mathrm{g} / \mathrm{L}$ (5). The median UIC values for United States pregnant women was $129 \mu \mathrm{g} / \mathrm{L}$, which is consistent with a mild iodine deficiency (6). The American Thyroid Association (ATA) recommends that women who are planning to become pregnant or who are pregnant should supplement their diets with $150 \mu \mathrm{g} /$ day of iodine (3).

Thyroid size is a sensitive marker for severe iodine deficiency because a goitre can be easily assessed by a physical examination and by a thyroid ultrasound. During pregnancy, the thyroids of mothers in iodinedeficient (moderate to low) areas will increase in size due to autoregulatory mechanisms of iodine on thyroid growth (7). There are limited data from pregnant women living in iodine-sufficient areas.

sTg also is a sensitive marker of iodine status as it reflects thyroid activity and hyperplasia (8). In iodinedeficient infants and children, the sTg concentrations are high, more often than are the serum TSH concentrations (9). Therefore, the sTg levels should be a good indicator of iodine nutrition in the general population and also in pregnant women (10).

Since 1953, salt iodization has been mandatory in Brazil, which is now reported to be an iodine-intakeadequate area with median UIC $276 \mu \mathrm{g} / \mathrm{L}$, which was previously categorized as 'more than adequate' category (http://www.ign.org). However, iodine deficiency is still observed in a significant proportion of schoolchildren, especially from poor and uneducated families and rural regions (11). Previous small studies carried out in Brazil demonstrated an insufficient iodine intake in pregnant women, alerting about the adequacy of the iodine supply in Brazil, especially regarding the new determinations of the Brazilian government that recently reduced the concentrations of iodine in table salt to $15-45 \mathrm{mg} / \mathrm{kg}$ of salt (12).

We conducted this study to evaluate iodine status according to the median UIC, sTg and thyroid volume (TV) by ultrasound and thyroid function in pregnant women living in iodine-adequate areas during the three trimesters of pregnancy.

\section{Materials and methods}

This cross-sectional study included 312 pregnant women who were consecutively recruited from the University Hospital Obstetric Outpatient Clinic and from the Einstein programme at Paraisopolis Community, both located in Sao Paulo (Sao Paulo State, Brazil) between April 2012 and June 2016. The exclusion criteria were ages less than 18 years, twin pregnancies, high-risk pregnancies (kidney disorders, hypertension, diabetes and HIV-positive), preeclampsia and known thyroid disease. Women taking iodine-containing supplements and thyroxine or drugs that interfere with thyroid function (amiodarone, glucocorticoid, lithium, biotin, metformin) also were excluded from the study.

The first analysis excluded pregnant women with thyroperoxidase antibody-positive and/or thyroglobulin antibody (TgAb)-positive measured by electrochemiluminescence immunoassays (ECLIA) methods (Roche Diagnostics, Mannheim, Germany and Beckman Coulter, Fullerton, USA). Pregnant women with $\mathrm{TSH}>10 \mathrm{mIU} / \mathrm{L}$ were also excluded. The remaining 273 pregnant women were analyzed according to thyroid function, sTg, ultrasound examination of thyroid gland and UIC at each trimester.

The study was approved by the Institutional Ethical Committee of our Institution (Hospital das Clinicas HCFMUSP, CAPPesq $\mathrm{n}^{\circ}$ 01503912.8.0000.0068). Written consent was obtained from all participants.

\section{Biochemical and hormonal measurements}

TSH, total and free T3 (TT3 and fT3), total and free T4 (TT4 and fT4), sTg and UIC were measured in all pregnant women. Blood and urine samples were collected between 08:00 and $10: 00 \mathrm{~h}$ and were maintained at $-20^{\circ} \mathrm{C}$ until measurement. The ECLIA were used to measure serum 
thyroid hormones (Roche Diagnostics, Mannheim, Germany and Beckman Coulter, Fullerton, USA), and all samples were measured in duplicate.

According to the manufacturer, the reference values for the non-pregnant population were $0.27-4.20 \mathrm{mIU} / \mathrm{L}$ for TSH; $1.3-3.1 \mathrm{nmol} / \mathrm{L}$ for TT3; 3.1-6.8 pmol/L for fT3; 66-181 nmol/L for TT4 and 12.0-22.0 pmol/L for fT4.

Spot morning urine samples $(10 \mathrm{~mL})$ were collected after overnight fasting from all participants in universal containers and transferred to Monovette tubes for transport and storage at $-20^{\circ} \mathrm{C}$ until analysis. The adapted Sandell-Kolthoff reaction was used to determine the UIC, and all samples were measured in duplicate (13).

\section{Thyroid ultrasonography}

A thyroid ultrasound was performed on each pregnant woman by the same physician (Ana Carolina de Castro Nassif Gomes Monteiro) using a $7.5-12 \mathrm{MHz}$ linear probe with a colour Doppler ultrasound programme (Philips IU-22, USA). Volumes of each thyroid lobe were calculated according to the rotation ellipsoid model: total $\mathrm{TV}(\mathrm{mL})=$ right lobe volume + left lobe volume + isthmus volume, considering depth $(\mathrm{cm}) \times$ width $(\mathrm{cm}) \times$ length $(\mathrm{cm}) \times \pi / 6$ for each lobe. The thyroid echogenicity was characterized as normal or hypoechoic in comparison to cervical muscle echogenicity.

\section{Statistical analysis}

Data were analysed using IBM SPSS statistics for windows (Version 22.0.) and Minitab 17 statistical software
(Version 2010; State College, PA, USA). Results were expressed as mean \pm s.D. The normality tests used were Kolmogorov-Smirnov or Shapiro-Wilk. Comparisons between the numerical variables were performed by Student's $t$-test and one-way ANOVA while non-normal distribution was performed using Mann-Whitney and Kruskal-Wallis tests. The Bonferroni post hoc-test was applied to adjust for multiple comparisons. A $P$ value of less than 0.05 was considered statistically significant.

\section{Results}

A total of 273 pregnant women were evaluated, with mean ages of $28.1 \pm 6.5$ years, mean BMI of $26.2 \pm 4.9 \mathrm{~kg} / \mathrm{m}^{2}$, and $40 \%$ were primigravida. Clinical characteristics of the study population according to each trimester of pregnancy are shown in Table 1.

The median UIC of all pregnant women was $144 \mu \mathrm{g} / \mathrm{L}$ (range 27.3-403), which is indicative of iodine deficiency according to the World Health Organization (WHO) criteria for pregnant women (5). A UIC of $<150 \mu \mathrm{g} / \mathrm{L}$ was found in $52 \%$ of the women, and a UIC of $<50 \mu \mathrm{g} / \mathrm{L}$ was found in only $2 \%$. Adequate iodine status $(150-249 \mu \mathrm{g} / \mathrm{L})$ was observed in $44 \%$ of the women, and only $4 \%$ had a UIC of $\geq 250 \mu \mathrm{g} / \mathrm{L}$. The UIC showed no statistic differences among the trimesters of pregnancy, also considering percentiles 25th and 75th. Iodine deficiency status was more frequent in the third trimester, but the lowest median UIC was found in the first trimester $(135 \mu \mathrm{g} / \mathrm{L})$.

The mean TSH values were $1.50 \pm 0.92,2.03 \pm 1.03$ and $1.91 \pm 0.96 \mathrm{mIU} / \mathrm{L}$, in the first, second and third trimesters,

Table 1 Demographic characteristics of the pregnant women in each trimester.

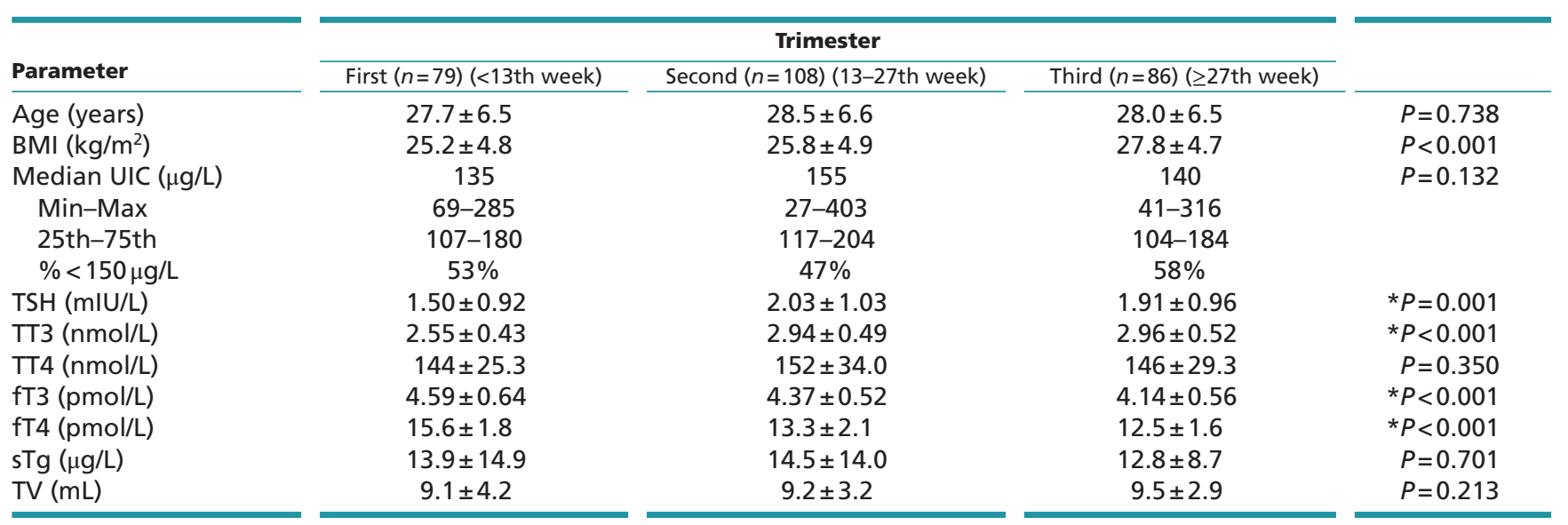

$P$ value $<0.05$ was considered statistically significant.

* $P$ values for the comparison between first and second trimester and first and third trimester.

sTg, serum thyroglobulin; TV, thyroid volume; UIC, urinary iodine concentration.

$$
\begin{array}{lr}
\text { http://www.endocrineconnections.org } & \text { ○ } 2018 \text { The authors } \\
\text { https://doi.org/10.1530/EC-18-0131 } & \text { Published by Bioscientifica Ltd }
\end{array}
$$


respectively ( $P=0.001$ for all trimesters). The fT4 and fT3 values decreased significantly during pregnancy $(P<0.001$ for all trimesters) (Table 1$)$. The TT4 and TT3 concentrations were higher during pregnancy. The TT4 concentrations remained stable throughout pregnancy, but the TT3 concentrations increased during consecutive trimesters, which was $29 \%$ higher than the reference values for the non-pregnant population.

The sTg levels did not change significantly during the trimesters $(13.9 \pm 14.9,14.5 \pm 14.0$ and $12.8 \pm 8.7 \mathrm{ng} / \mathrm{mL}$, respectively). The median $\mathrm{sTg}$ was $11.2 \mathrm{ng} / \mathrm{mL}$, and sTg above $40 \mathrm{ng} / \mathrm{mL}$ was found in only $3.3 \%$ of studied patients.

The mean TV was $9.3 \pm 3.4 \mathrm{~mL}$, and only $4.5 \%$ had TV exceeding $15 \mathrm{~mL}$. The TV did not differ during pregnancy and positively correlated with the BMI $(r=0.319, P<0.001)$ (Fig. 1), but not with the sTg and TSH. We found no correlation between TV and UIC. A thyroid nodule was detected in 19\% of all pregnant patients.

When pregnant women were categorized as iodine deficient (UIC $<150 \mu \mathrm{g} / \mathrm{L}$ ), iodine adequate (UIC $\geq 150$ and $<250 \mu \mathrm{g} / \mathrm{L}$ ) and iodine excessive (UIC $\geq 250 \mu \mathrm{g} / \mathrm{L}$ ), concentrations of sTg, thyroid hormones and TV at each trimester had no statistical difference according to the iodine status groups (Table 2).

\section{Discussion}

In the present study, we support that iodine deficiency is frequent in pregnant women living in an area of adequate iodine consumption. According to WHO recommendation, in our cohort, iodine deficiency is considered mild, with a median of $144 \mu \mathrm{g} / \mathrm{L}$. Several reports

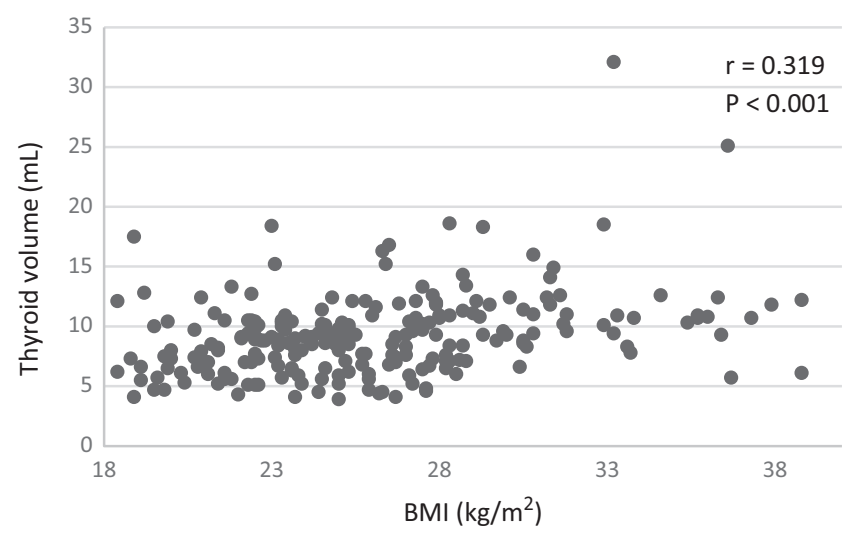

Figure 1

Relationship between body BMI and TV in pregnant women from an adequate iodine area. TV, thyroid volume.

http://www.endocrineconnections.org https://doi.org/10.1530/EC-18-0131

(C) 2018 The authors Published by Bioscientifica Ltd described iodine-deficient pregnant women even in iodinesufficient areas, despite the existence of an iodization programme, and pregnant women are considered a risk group $(3,12)$. In Brazil, the salt iodization programme is successful at combating iodine deficiency, but ongoing monitoring is mandatory as Brazil is a continental country with vulnerable regions, such as rural areas and lower economic conditions (11). Recently, the Brazilian government's salt iodization programme reduced the iodine concentration in salt from $40-60 \mathrm{mg} / \mathrm{kg}$ to $15-45 \mathrm{mg} / \mathrm{kg}$ based on previous reports pointing to excessive iodine intake (14). Our data were collected before the lower iodine concentration in salt was enacted, reinforcing the high risk of iodine deficiency in pregnant women in the next few years. Brazil also has no iodine supplementation programme for pregnant and lactating women as suggested in recent ATA guidelines, which recommend iodine-containing supplements $(3,12,15)$.

Few reports analysed the UIC, thyroid function and TV with sTg in each trimesters of pregnancy. Thyroid hormonal findings here reflect the well-known physiological change: TSH increments, high levels of TT3 and TT4 and trend to lower fT4 and fT3 in the second and third trimesters of pregnancy. No differences in thyroid function were found according to iodine intake as previously described $(10,16)$.

The sTg is speculated to be a sensitive indicator of both low and excessive iodine intake (17). Zimmermann et al. suggested a median sTg of $<13 \mu \mathrm{g} / \mathrm{L}$ and/or $<3 \%$ of sTg values $>40 \mu \mathrm{g} / \mathrm{L}$ indicates an iodine sufficiency in the population (18). Recently, Bath et al. performed sTg in pregnant women and found a negative association between iodine status (measured by the iodine-to-creatinine ratio) and sTg concentrations (10). The sTg was higher in the iodine-deficient group compared to the iodine-sufficient group, especially in later pregnancy. It is noteworthy that $15.7,8.7$ and $18.4 \%$ of women had a $s T g>40 \mu \mathrm{g} / \mathrm{L}$ in each trimester, independent of iodine status, and the median sTg was 21,19 and $23 \mu \mathrm{g} / \mathrm{L}$, respectively, in each trimester. In our study, the median sTg was 10.8, 11.3 and $11.2 \mu \mathrm{g} / \mathrm{L}$, respectively, in each trimester, and only $3.3 \%$ of pregnant women had a sTg $>40 \mu \mathrm{g} / \mathrm{L}$ (3 patients in the first trimester, 5 in the second and 1 in the third). Therefore, sTg concentrations were not useful to determine iodine status in our cohort.

Thyroid enlargement also is an indicator of insufficient iodine intake, and $10-15 \%$ of pregnant women in areas with low iodine intake develop a goitre, besides the physiologic increment due to normal pregnancy (19). In the present study, we did not observe

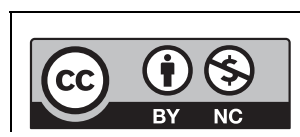

This work is licensed under a Creative Commons Attribution-NonCommercial 4.0 International License. 
Table 2 Thyroid parameters according to iodine status in the pregnant women.

\begin{tabular}{|c|c|c|c|}
\hline & \multirow[b]{2}{*}{ lodine status } & \multicolumn{2}{|r|}{ First } \\
\hline & & $N$ & Mean \pm S.D. \\
\hline \multirow{2}{*}{ TT3 (nmol/L) } & Deficiency & 42 & $2.60 \pm 0.42$ \\
\hline & Adequate & 36 & $2.51 \pm 0.44$ \\
\hline \multirow[t]{2}{*}{ TT4 (nmol/L) } & Deficiency & 42 & $148 \pm 26.8$ \\
\hline & Adequate & 36 & $141 \pm 23.4$ \\
\hline \multirow[t]{2}{*}{ fT3 (pmol/L) } & Deficiency & 42 & $4.62 \pm 0.59$ \\
\hline & Adequate & 36 & $4.49 \pm 0.68$ \\
\hline \multirow[t]{2}{*}{ fT4 (pmol/L) } & Deficiency & 42 & $15.6 \pm 1.7$ \\
\hline & Adequate & 36 & $15.6 \pm 1.8$ \\
\hline \multirow[t]{2}{*}{ TSH (mIU/L) } & Deficiency & 42 & $1.63 \pm 0.95$ \\
\hline & Adequate & 36 & $1.34 \pm 0.88$ \\
\hline \multirow[t]{2}{*}{$s T g(\mu g / L)$} & Deficiency & 42 & $14.7 \pm 17.9$ \\
\hline & Adequate & 36 & $13.2 \pm 10.8$ \\
\hline \multirow[t]{2}{*}{ TV (mL) } & Deficiency & 38 & $8.5 \pm 2.9$ \\
\hline & Adequate & 29 & $9.8 \pm 5.4$ \\
\hline
\end{tabular}

\begin{tabular}{|c|c|c|}
\hline \multirow[b]{2}{*}{$P$} & \multicolumn{2}{|r|}{ Second } \\
\hline & $N$ & Mean \pm S.D. \\
\hline \multirow[t]{2}{*}{0.360} & 51 & $3.04 \pm 0.48$ \\
\hline & 49 & $2.83 \pm 0.46$ \\
\hline \multirow[t]{2}{*}{0.402} & 51 & $156 \pm 33.4$ \\
\hline & 49 & $149 \pm 35.7$ \\
\hline \multirow[t]{2}{*}{0.760} & 51 & $4.31 \pm 0.55$ \\
\hline & 49 & $4.23 \pm 0.49$ \\
\hline \multirow[t]{2}{*}{0.999} & 51 & $13.4 \pm 2.2$ \\
\hline & 49 & $13.2 \pm 2.1$ \\
\hline \multirow[t]{2}{*}{0.376} & 51 & $2.27 \pm 1.05$ \\
\hline & 49 & $1.79 \pm 1.01$ \\
\hline \multirow[t]{2}{*}{0.727} & 51 & $15.8 \pm 17.0$ \\
\hline & 48 & $13.4 \pm 11.1$ \\
\hline \multirow[t]{2}{*}{0.447} & 48 & $9.2 \pm 2.7$ \\
\hline & 45 & $9.2 \pm 3.8$ \\
\hline
\end{tabular}

\begin{tabular}{c}
$\frac{\boldsymbol{P}}{0.077}$ \\
0.432 \\
0.696 \\
0.586 \\
0.062 \\
0.597 \\
0.946 \\
\hline
\end{tabular}

\begin{tabular}{|c|c|c|}
\hline \multicolumn{2}{|r|}{ Third } & \multirow[b]{2}{*}{$\boldsymbol{P}$} \\
\hline$N$ & Mean \pm s.D. & \\
\hline 50 & $2.89 \pm 0.54$ & 0.408 \\
\hline 32 & $2.99 \pm 0.50$ & \\
\hline 49 & $140 \pm 20.3$ & 0.075 \\
\hline 32 & $151 \pm 34.6$ & \\
\hline 50 & $4.15 \pm 0.57$ & 0.898 \\
\hline 32 & $4.15 \pm 0.58$ & \\
\hline 49 & $12.3 \pm 1.5$ & 0.552 \\
\hline 32 & $12.7 \pm 1.7$ & \\
\hline 50 & $1.85 \pm 0.91$ & 0.154 \\
\hline 32 & $1.95 \pm 1.06$ & \\
\hline 50 & $12.5 \pm 8.7$ & 0.617 \\
\hline 32 & $12.9 \pm 8.6$ & \\
\hline 43 & $9.4 \pm 2.9$ & 0.996 \\
\hline 30 & $9.5 \pm 2.8$ & \\
\hline
\end{tabular}

Values are expressed as mean \pm S.D. $N=$ number of pregnant women evaluated. Epidemiological criteria for assessing iodine nutrition in pregnant women according to World Health Organization (WHO): iodine deficiency UIC $<150 \mu \mathrm{g} / \mathrm{L}$ and iodine adequate $\mathrm{UIC}>150$ and $<249 \mu \mathrm{g} / \mathrm{L}$. $P$ value for the comparison between iodine deficiency and adequate status in the trimesters. STg, serum thyroglobulin; TV, thyroid volume; UIC, urinary iodine concentration.

increments in TV during pregnancy or a higher frequency of goitres with no increment of sTg, probably because most women were mild iodine deficient so no differences in TSH concentrations were found. Although we found no difference in TV during pregnancy, TV was positively related with BMI, independent of the trimester. The effect of TSH on thyroid hyperplasia must be discreet since TSH levels remained in the normal range, and BMI was not correlated with iodine status and TSH. Our data indicate that a higher BMI increases TV mostly due to extracellular fluid expansion and blood volume increments that occur during normal pregnancy (20).

In the present paper, a 97\% TSH concentration was $4.21 \mathrm{mIU} / \mathrm{L}$, similar to previously described iodinesufficient pregnant populations, and our frequency of subclinical hypothyroidism was 3.6\% when considering a TSH of $<4 \mathrm{mIU} / \mathrm{L}$ (3).

Our study had several limitations, as a dietary intake of iodine survey was not performed as well as the limited number of pregnant women evaluated in each trimester. Although the median UIC is a well-known indicator of iodine intake for the population, individual intakes are highly variable, and a low UIC on any given day might be found despite adequate daily intakes to maintain thyroidal iodine stores (21). Our study did not evaluate the socioeconomic and educational statuses that are associated with iodine deficiency (11).

Caution in accepting the necessity of iodine supplementation has been expressed, especially in areas where iodized salt is already in use (22). However, our findings reinforce a worldwide concern about the adequacy of the iodine intake of pregnant women.

http://www.endocrineconnections.org https://doi.org/10.1530/EC-18-0131

(c) 2018 The authors Published by Bioscientifica Ltd
The iodine status evaluation in pregnant women must be reassessed with UIC, as it is the most appropriate method, in regular intervals to assess adequate intake and recommend supplementation if necessary. The Brazilian salt iodization programme prevents iodine deficiency but does not maintain iodine status within an adequate and recommended range for pregnant women, and ongoing vigilance is mandatory after the recent reduction of iodine in table salt (12).

In conclusion, iodine deficiency was found in $52 \%$ of pregnant women living in iodine-adequate areas. The sTg concentration and TV were not feasible to use as iodine status markers.

\section{Declaration of interest}

The authors declare that there is no conflict of interest that could be perceived as prejudicing the impartiality of the research reported.

\section{Funding}

This study was supported by the Fundacao de Amparo a Pesquisa do Estado de Sao Paulo (FAPESP 2012/03732-0) and Coordenacao de Aperfeicoamento de Pessoal de Nivel Superior (CAPES).

\section{Acknowledgements}

We would like to thank the staff of Clinic of the Paraisopolis Community (Hospital Albert Einstein Project) for their assistance and Dr Raymundo Soares de Azevedo Neto for the statistical analysis.

\section{References}

1 Glinoer D. The importance of iodine nutrition during pregnancy. Public Health Nutrition 200710 1542-1546. (https://doi.org/10.1017/ S1368980007360886)

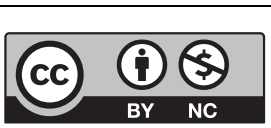

This work is licensed under a Creative Commons Attribution-NonCommercial 4.0 International License. 
2 de Escobar GM, Obregón MJ \& del Rey FE. Iodine deficiency and brain development in the first half of pregnancy. Public Health Nutrition 200710 1554-1570. (https://doi.org/10.1017/ S1368980007360928)

3 Alexander EK, Pearce EN, Brent GA, Brown RS, Chen H, Dosiou C, Grobman W, Laurberg P, Lazarus JH, Mandel SJ, et al. 2017 Guidelines of the American Thyroid Association for the diagnosis and management of thyroid disease during pregnancy and the postpartum. Thyroid 201727 315-389. (https://doi.org/10.1089/ thy.2016.0457)

4 Brander L, Als C, Buess H, Haldimann F, Harder M, Hänggi W, Herrmann U, Lauber K, Niederer U, Zürcher T, et al. Urinary iodine concentration during pregnancy in an area of unstable dietary iodine intake in Switzerland. Journal of Endocrinological Investigation 200326 389-396. (https://doi.org/10.1007/BF03345192)

5 World Health Organization, United Nations Children's Fund \& Disorders ICfCoID. Assessment of Iodine Deficiency Disorders and Monitoring their Elimination: A Guide for Programme Managers. Genova, Switzerland: WHO Press, 2007.

6 Caldwell KL, Makhmudov A, Ely E, Jones RL \& Wang RY. Iodine status of the U.S. population, National Health and Nutrition Examination Survey, 2005-2006 and 2007-2008. Thyroid 201121 419-427. (https://doi.org/10.1089/thy.2010.0077)

7 Berghout A \& Wiersinga W. Thyroid size and thyroid function during pregnancy: an analysis. European Journal of Endocrinology 1998138 536-542. (https://doi.org/10.1530/eje.0.1380536)

8 Ma ZF \& Skeaff SA. Thyroglobulin as a biomarker of iodine deficiency: a review. Thyroid 201424 1195-1209. (https://doi. org/10.1089/thy.2014.0052)

9 Vejbjerg P, Knudsen N, Perrild H, Laurberg P, Carlé A, Pedersen IB, Rasmussen LB, Ovesen L \& Jørgensen T. Thyroglobulin as a marker of iodine nutrition status in the general population. European Journal of Endocrinology 2009161 475-481. (https://doi. org/10.1530/EJE-09-0262)

10 Bath SC, Pop VJ, Furmidge-Owen VL, Broeren MA \& Rayman MP. Thyroglobulin as a functional biomarker of iodine status in a cohort study of pregnant women in the United Kingdom. Thyroid 201727 426-433. (https://doi.org/10.1089/thy.2016.0322)

11 Campos ReO, Reboucas SC, Beck R, de Jesus LR, Ramos YR, Barreto IoS, Marques TX, Cerqueira TL, Santos WA, Oliveira CA, et al. Iodine nutritional status in schoolchildren from public schools in Brazil: a cross-sectional study exposes association with socioeconomic factors and food insecurity. Thyroid 201626 972-979. (https://doi. org/10.1089/thy.2015.0448)
12 Ferreira SM, Navarro AM, Magalhães PK \& Maciel LM. Iodine insufficiency in pregnant women from the State of São Paulo. Arquivos Brasileiros de Endocrinologia e Metabologia 201458 282-287. (https://doi.org/10.1590/0004-2730000002979)

13 Carvalho AL, Meirelles CJ, Oliveira LA, Costa TM \& Navarro AM. Excessive iodine intake in schoolchildren. European Journal of Nutrition 201251 557-562. (https://doi.org/10.1007/s00394-011-0239-7)

14 Medeiros-Neto G. Iodine nutrition in Brazil: where do we stand? Arquivos Brasileiros de Endocrinologia e Metabologia 200953 470-474. (https://doi.org/10.1590/S0004-27302009000400014)

15 Campos ReO, Barreto IoS, Maia LR, Rebouças SC, Cerqueira TL, Oliveira CA, Santos CA, Mendes CM, Teixeira LS \& Ramos HE. Iodine nutritional status in Brazil: a meta-analysis of all studies performed in the country pinpoints to an insufficient evaluation and heterogeneity. Archives of Endocrinology and Metabolism 201559 13-22. (https://doi.org/10.1590/2359-3997000000004)

16 Anaforoğlu İ, Algün E, İnceçayır Ö, Topbaş M \& Erdoğan MF. Iodine status among pregnant women after mandatory salt iodisation. British Journal of Nutrition 2016115 405-410.

17 Zimmermann MB, Aeberli I, Andersson M, Assey V, Yorg JA, Jooste P, Jukić T, Kartono D, Kusić Z, Pretell E, et al. Thyroglobulin is a sensitive measure of both deficient and excess iodine intakes in children and indicates no adverse effects on thyroid function in the UIC range of 100-299 $\mu \mathrm{g} / \mathrm{L}$ : a UNICEF/ICCIDD study group report. Journal of Clinical Endocrinology and Metabolism 201398 1271-1280. (https://doi.org/10.1210/jc.2012-3952)

18 Zimmermann MB. The importance of adequate iodine during pregnancy and infancy. World Review of Nutrition and Dietetics 2016 115 118-124.

19 Zimmermann MB. Iodine deficiency. Endocrine Reviews 200930 376-408. (https://doi.org/10.1210/er.2009-0011)

20 Vannucchi G, Covelli D, Vigo B, Perrino M, Mondina L \& Fugazzola L. Thyroid volume and serum calcitonin changes during pregnancy. Journal of Endocrinological Investigation $2017 \mathbf{4 0} 727-732$ (https://doi.org/10.1007/s40618-017-0622-1)

21 König F, Andersson M, Hotz K, Aeberli I \& Zimmermann MB. Ten repeat collections for urinary iodine from spot samples or 24-hour samples are needed to reliably estimate individual iodine status in women. Journal of Nutrition 2011141 2049-2054.

22 Menéndez Torre E, Delgado Alvarez E, Rabal Artal A, Suárez Gutiérrez L, Rodríguez Caballero MG, Ares Blanco J, Díaz Naya L \& Fernández Fernández JC. Iodine nutrition in pregnant women from Oviedo area. Is iodine supplementation necessary? Endocrinología y Nutrición 201461 404-409.

Received in final form 23 April 2018

Accepted 26 April 2018

Accepted Preprint published online 26 April 2018 http://www.endocrineconnections.org https://doi.org/10.1530/EC-18-0131 (c) 2018 The authors Published by Bioscientifica Ltd

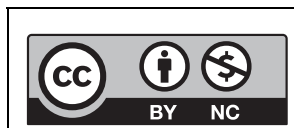

This work is licensed under a Creative Commons Attribution-NonCommercial 4.0 International License. 